\title{
Reply to Comment on "A New Technique to Avoid Sternotomy in Retrosternal Thyroid Surgery"
}

\author{
Rojan Kuruvilla ${ }^{1}$
}

(c) Association of Surgeons of India 2021

Thank you for your comments on the article. Regarding whether nodules were seen on CECT, the authors have clearly mentioned in the article that all patients had CECT showing multinodular goiter in the retrosternal portion as well and images of one of these were included. FNAC was done from the most prominent nodule in the cervical portion of the gland. The authors have not included any patients with suspicion of malignancy in this study, and also mentioned that this method should not be done in case of suspicion of malignancy. The whole of the retrosternal portion was not pulverized. Only debulking to facilitate easy delivery into the neck was done. Regarding chance of rupturing an occult malignant nodule, the authors have used CUSA setting as for liver surgery, a setting that will not be able to rupture a hard or firm malignant nodule. Intraoperative nerve monitoring was not used as we don't have the facility. Agree that it would be a real help in these types of cases. Regret the omission of ethical declarations. However, all patients consented for sternotomy in case of failure to deliver the gland through the cervical incision.

Publisher's Note Springer Nature remains neutral with regard to jurisdictional claims in published maps and institutional affiliations.
Rojan Kuruvilla

rojank@yahoo.com

1 Department of General Surgery, ASTER Malabar Institute of Medical Sciences Ltd, Govindapuram, Kozhikode, Kerala 673016, India 